\title{
Effect of cavity preparation on the flexural strengths of acrylic resin repairs
}

\author{
Safa Salim ELHADIRY', Norsiah YUNUS², Yusnidar Tajul ARIFFIN²
}

1- BDS, MDS, Lecturer, Department of Prosthodontics, Faculty of Dentistry, Al-Fatah University of Medical Science, Tripoli, Libya.

2- BDS, MSc, Associate Professor, Department of Prosthetic Dentistry, Faculty of Dentistry, University of Malaya, Kuala Lumpur, Malaysia.

Corresponding address: Associate Professor Dr Norsiah Yunus - Department of Prosthetic Dentistry - Faculty of Dentistry - University of Malaya - 50603 Kuala Lumpur - Malaysia - Phone: 603-79674881 - Fax: 603-79674535 - e-mail: norsiah@um.edu.my

Received: March 12, 2009 - Modification: September 7, 2009 - Accepted: February 16, 2010

\section{ABSTRACT}

\begin{abstract}
O bjective: To investigate the effect of cavity preparation on the flexural strength of heatcuring denture resin when repaired with an auto-curing resin. Material and methods: Ninety-six rectangular specimens $(64 \times 10 \times 2.5 \mathrm{~mm})$ prepared from heat-curing denture base resin (Meliodent) were randomly divided into four groups before repair. One group was left intact as control. Each repair specimen was sectioned into two; one group was repaired using the conventional repair method (Group 1 ). Two groups had an additional transverse cavity $(2 \times 3.5 \times 21.5 \mathrm{~mm})$ prepared prior to the repair; one repaired with (Group 2 ) and one without glass-fiber reinforcement (Group 3). A three-point flexural bending test according to the ISO 1567:1999 specification ${ }^{8}$ for denture base polymers was carried out on all groups after 1, 7 and 30 days of water immersion. Statistical analysis was carried out using two-way ANOVA, Kruskal Wallis and post-hoc Mann Whitney tests. Results: The highest flexural strength was observed in the control group. Control and conventional repairs group (Group 1) showed reduction in the flexural strength 30 days after water immersion. No significant change in the strength was observed for Groups 2 and 3 where the repair joints were similarly prepared with additional transverse cavity. Conclusion: Repaired specimens showed lower flexural strength values than intact heat-curing resin. Cavity preparation had no significant effect on the flexural strength of repair with water immersion.
\end{abstract}

Key words: Denture repair. Glass fibers reinforcement. Cavity preparation. Flexural strength.

\section{INTRODUCTION}

Polymethyl methacrylate is the most commonly used denture base resin. Many studies had shown that the material has higher levels of impact, fatigue and flexural strengths than other denture resins ${ }^{10,29,30}$. However, fracture of removable prosthesis constructed from this material is still a common clinical occurrence 4,5 . A common measure to solve the situation is to temporarily or definitively repair the denture. One of the problems with denture repair, however, is that it is weaker than the original prosthesis and may re-fracture within a short period of time. Often it occurs at the interface junction of the original base and repair materials ${ }^{23}$. This may be related to the weak adhesion between the old denture and new repair resin ${ }^{9}$.

There are many factors affecting successful repair such as the materials used for repair, the surface contour of repair joints, joint surface gap between the repair ends, repair technique, and treatment given to the joint surfaces before repair

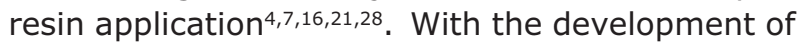
glass-fiber reinforced composites in the industry, this has also inspired a new approach to improve the performance of acrylic denture repair. A clinical study ${ }^{27}$ has shown that glass fiber-reinforced repaired denture did not re-fracture in the same location of the previous repair indicating the strengthening effect of the glass fiber. Improvement in fracture resistant of the repair when glass fiber was used for repair had also been reported ${ }^{13,20}$. And for the placement of reinforcement materials, additional central cavity was created within the specimens to accommodate the fibers. However, the effect of these cavities alone was not investigated and therefore it could not be certain the role played by the cavity preparation. On the other hand, 
most in-vitro studies on reinforced denture repair concentrated mainly on the effect of different type of reinforcements ${ }^{11,20}$ even though the longevity of the repair with water immersion is also considered to be clinically important.

The objective of this study was to evaluate the flexural strength of one glass fiber-reinforced repair and two non-reinforced repairs with and without cavity preparation 1,7 and 30 days after water immersion.

\section{MATERIAL AND METHODS}

Ninety-six rectangular specimens $(64 \times 10 \times 2.5$ $\mathrm{mm}$ were fabricated from heat-curing acrylic resin (Meliodent, Bayer, Newbury, UK) by investing a perspex block (Plexiglass, London, UK) in dental stone. Twenty-three gram of powder and $10 \mathrm{ml}$ of liquid of acrylic resin were proportioned, mixed, packed and processed into the mold following the manufacturer's instruction. Polymerization was conducted in a water bath (Acrydig10, Menfredi, Torino, Italy) with a long curing cycle of $70^{\circ} \mathrm{C}$ for 7 $\mathrm{h}$ followed by $100^{\circ} \mathrm{C}$ for $1 \mathrm{~h}$. After deflasking, the specimens were trimmed and polished and then immersed in water at $37^{\circ} \mathrm{C}$ for 1 month to allow water saturation $22,25,26$.

Specimens were randomly divided into 4 groups $(n=24)$. One group was left intact without repair (control). The rest of the specimens were cut into 2 halves with the joint ends rounded off as this type of joint preparation has been shown to provide the strongest repair ${ }^{28}$. For each repair specimen, an index was made by making an open-ended stone mold that allowed the repair ends to be moved providing a $2 \mathrm{~mm}$ gap between them. The gap was filled with the auto-curing repair resin (Meliodent) using mixing powder:liquid ratio of $10 \mathrm{~g}$ powder for $7 \mathrm{~mL}$ liquid, following the manufacturer's instruction. Polymerization was carried out in a pressure pot (Leone s.p.s., Firenze, Italy) for 10 min at a pressure of 2.2 bar and a temperature of $45^{\circ} \mathrm{C}$ following the manufacturer's instruction. One of the groups was prepared using conventional repair method (Group 1) where the joints were rounded before repair resin was applied. The other two repair groups had in addition a transverse cavity measuring $2 \times 3.5 \times 21.5 \mathrm{~mm}$ prepared at the joint ends; one group was repaired with E-glass fiber (Fiber-Splint ${ }^{\mathrm{TM}}$ Lab-System, Polydentia SA, Mezzovico, Switzerland), embedded within the cavity (Group 2), while the other group was repaired without fiber reinforcement (Group 3). FiberSplint $^{\mathrm{TM}}$ consisted of multiple layers of silanized E-glass fiber strips and each layer consisted of unidirectional fibers which were plaited in each other to form woven glass fibers. The manufacturer claimed that the silanization of the glass fiber strip gives good bond with the resin. From the pilot study, 2 layers of fibers with standardized weight of $0.01 \mathrm{~g}$ were used for reinforced repair specimen (Group 2). The glass-fiber was impregnated with light-curing adhesive resin (Fiber-bond, Polydentia SA, Mezzovico, Switzerland) as recommended by the manufacturer. This acted as a wetting agent that improved the adhesion between the glass-fiber and auto-curing repair resin. A light-curing unit (QHL 75, Dentsply/DeTrey, Konstanz, Germany) was used to polymerize the resin before repair resin was filled in the gap.

The groups were further subdivided into 3 groups according to the time of water storage at $37^{\circ} \mathrm{C}$ before the flexural strength test $(n=8): 1$ day, 7 days and 30 days.

The flexural strength was determined using a three-point flexural bending test according to the ISO 1567:1999 specification ${ }^{8}$ for denture base polymers. It was conducted on an Instron Universal Testing Machine (Model 4302; Instron Inc., High Wycombe, UK). The crosshead speed during the test was $5 \mathrm{~mm} / \mathrm{min}$ and the test was carried out in a water bath at $37^{\circ} \mathrm{C}$.

The flexural strength (S) was computed from the equation:

$\mathrm{S}=3 \mathrm{NI} / 2 \mathrm{bd} \mathrm{d}^{2}$

Where " $\mathrm{N}$ " is the maximum force $(\mathrm{N})$, "I" was the distance between supports $(50 \mathrm{~mm})$, "b" was the width, and " $d$ " was the depth of specimen.

Data were statistically analyzed by 2-way ANOVA for the effect of repair method, immersion period and interaction. Kruskal Wallis and post-hoc MannWhitney with Bonferroni correction were used for analysis within repair method and within immersion period. All tests used a 0.05 level of statistical significance. Statistical calculations were performed using SPSS for Windows (Release 12.01, SPSS Inc., Chicago, IL, USA).

The fracture ends were inspected using a stereomicroscope (Kyowa SD-2PL, Tokyo, Japan) at a magnification of $\times 10$ to determine the mode of failure at bonding interface. The nature of failure was categorized adhesive (occurred at repair-denture base interface), cohesive (within the repair material) and mixed (at interface and repair material). One examiner was involved with the recording.

\section{RESULTS}

The mean flexural strength values of intact and repair groups are shown in Table 1 . The result of 2-way ANOVA showed that there was a statistically significant difference for the effect of repair methods $(p<0.001)$, the immersion periods $(p<0.001)$ and the interaction between the two factors $(p<0.001)$. Kruskall Wallis and post-hoc Mann Whitney analysis 
Table 1- Flexural strength (MPa) of repair groups at different immersion period

\begin{tabular}{lccc}
\hline Group & \multicolumn{3}{c}{ Immersion period (days) } \\
\hline & 1 day & 7 days & 30 days \\
Control & $81.69+2.23^{\mathrm{a}}$ & $79.71+1.48^{\mathrm{a}}$ & $73.44+4.16$ \\
1 & $54.88+4.41^{\mathrm{aA}}$ & $54.55+5.29^{\mathrm{aA}}$ & $33.55+5.54$ \\
2 & $61.89+1.93^{\mathrm{a}}$ & $61.90+2.12^{\mathrm{a}}$ & $62.19+3.87^{\mathrm{aA}}$ \\
3 & $50.03+6.24^{\mathrm{aA}}$ & $54.31+4.37^{\mathrm{aA}}$ & $52.93+7.84^{\mathrm{aA}}$ \\
\hline
\end{tabular}

Horizontally, means designated with the same superscripts were not statistically different between periods of immersion $(p>0.05)$

Vertically, means designated with the same capital letters were not statistically different between repair groups $(p>0.05)$

Table 2- Mode of failure (\%) of repair groups at various immersion periods

\begin{tabular}{llll}
\hline Group & \multicolumn{3}{c}{ Immersion periods (days) } \\
\hline & 1 days & 7 days & 30 days \\
& ${ }^{*} \mathrm{~A} / \mathrm{C} / \mathrm{M}$ & ${ }^{*} \mathrm{~A} / \mathrm{C} / \mathrm{M}$ & ${ }^{*} \mathrm{~A} / \mathrm{C} / \mathrm{M}$ \\
1 & $70 / 20 / 10$ & $80 / 10 / 10$ & $90 /-/ 10$ \\
2 & $60 / 40 /-$ & $60 / 40 /-$ & $80 / 10 / 10$ \\
3 & $-/ 20 / 80$ & $10 / 10 / 80$ & $-/-/ 100$ \\
\hline
\end{tabular}

${ }^{*} \mathrm{~A}=$ adhesive; $\mathrm{C}=$ cohesive; $\mathrm{M}=$ mixed modes of failures

showed no significant changes in the flexural strength values between the 3 periods of water immersion ( $p>0.05$ ) for Groups 2 and 3. However, Group 1 and control showed significant decrease in the mean flexural strength value after 30 days $(p<0.05)$. Post-hoc Mann Whitney analysis also revealed that at any period of water immersion, control group showed a significantly higher flexural strength value than all the repair groups $(p<0.05)$.

Analysis of failure (Table 2) showed that for Group 1, between $70-90 \%$ of specimens showed adhesive failure, while Group 3 exhibited mostly mixed type of adhesive and cohesive failure. Specimens with adhesive or cohesive failure in Group 2 were about equal in number with the percentage of specimens with adhesive failure increased after 30 days.

\section{DISCUSSION}

The denture base resin is used in a wet environment in the oral cavity. In addition to that, it is usually stored under water when it not in use. Therefore the influence of water on the mechanical properties is also an important factor to be investigated. It has been shown that the effect of water uptake by denture base polymers was to reduce their mechanical properties ${ }^{14,25}$. Similar results were observed in the present study with regards to the flexural strength of intact heat-curing PMMA and conventional repair group. $A$ reduction in the flexural strength recorded after
1 month of water immersion could be explained by the plasticization of the polymer matrix due to water absorption ${ }^{2}$.

In the glass fiber reinforced repair and nonreinforced repair where specimens were additionally prepared with central cavity perpendicular to the repair joints, no reduction in the flexural strength over the period of immersion was observed. Therefore based on this observation, the results suggested that the mechanical effects of cavity preparation may have played some role in stabilizing the strength of the repair. This could be explained by the increase in the surface area of interface between the repair and base materials, which might have enhanced the bonding between them.

A repair that deteriorates in strength over a short period of time reduces the clinical performance of the prosthesis. There are many available literatures reporting on various reinforcement materials that enhanced the repair strength ${ }^{13,20,23,26}$. However, research on the stability of fiber-reinforced repair is very limited. A clinical study reported re-fracture of removable prostheses after one year at other sites than previously repaired sites, indicating the effectiveness of reinforcement ${ }^{27}$. In the present study where the strength was determined 30 days after immersion in water, glass fiber-reinforced repair did not show significant deterioration in the strength. This was in contrast to the suggestion ${ }^{26}$ that water could act on the siloxane bond between the resin matrix and the pre-silanized E-glass-fiber to cause hydrolytic degradation. Some substances 
found in glass were thought to be reactive to water that could further decreased the hydrolytic stability of the reinforcement ${ }^{18}$. However in another study ${ }^{26}$, it was shown that E-glass fiber had relatively good long-term stability against water absorption, although the poor impregnation of fibers with polymer matrix predisposed the fibers-reinforced composite to water absorption. In the present study the fibers were carefully embedded within the repair material to ensure that they were not exposed to the environment. This could have reduced the hydrolytic degradation by water and hence leads to the observation of stability of the glass-fiber repair.

It was also observed in this study that the conventional repair exhibited flexural strength ranging between $46-67 \%$ of that of intact specimens. This range was comparable with another study which showed a reduction of between $36-65 \%$ of original strength $^{4}$. Berge, et al. ${ }^{3}$ (1983) revealed value of approximately $60 \%$, while Leong and Grant ${ }^{15}(1981)$ reported approximate value of $65 \%$. The reduction in flexural strength observed after repair which was in agreement with other findings $4,5,6,12,16,19,23,24$ could be related to the weak bond strength between denture base and repair resin ${ }^{16,17}$. The weak bond was also evident from the adhesive failure mostly observed in the specimens in this repair group. With inadequate bond strength, fracture through the repair sites was more common ${ }^{1}$. On the other hand, a higher percentage of specimens in non-reinforced repair group with cavity preparation exhibited mixed mode of failure. The same explanation as before can be made; with cavity preparation the surface area for bonding with repair material increased.

The limitations of this study were that the study design did not simulate the actual clinical situation: the specimen tested was different from the configuration of a denture and immersion in water did not actually represent the actual oral environment. Furthermore, only one type of fiberreinforcement was used. Further investigations are also necessary to evaluate the effect of aging on the mechanical performance of the repair over a longer period of time. Fatigue test, which simulates better the clinical forces, may also be suggested.

\section{CONCLUSION}

Within the limits of this study following conclusion were drawn:

None of the repair methods was able to restore the flexural strength of the heat-curing resin.

Cavity preparation had no significant effect on the flexural strength of repair with water immersion.

\section{REFERENCES}

1- Anusavice KJ, Phillips RW. Phillips' science of dental materials. $10^{\text {th }}$ ed. St. Louis: Elsevier; 2003.

2- Arima T, Murata H, Hamada T. Properties of highly crosslinked auto polymerizing reline acrylic resin. J Prosthet Dent. 1995;73(1):55-9.

3- Berge $\mathrm{M}$. Bonding strength of intact and repaired denture base resins. Acta Odontol Scand. 1983;41(3):187-91.

4- Beyli MS, von Fraunhofer JA. An analysis of causes of fracture of acrylic resin dentures. J Prosthet Dent. 1981;46(3):238-41.

5- Darbar UR, Huggett R, Harrison A. Denture fracture - a survey. Br Dent J. 1994;176(9):342-5.

6- Ellakwa AE, El-Sheikh AM. Effect of chemical disinfectants and repair materials on the transverse strength of repaired heatpolymerized acrylic resin. J Prosthodont. 2006;15(5):300-5.

7- Goiato MC, Pesqueira AA, Vedovatto E, Santos DM, Gennari Filho $\mathrm{H}$. Effect of different repair techniques on the accuracy of repositioning the fractured denture base. Gerodontology. $2009 ; 26(3): 237-41$.

8- International Standard Organization. ISO 1567:1999. Dentistrydenture base polymers. Geneva: International Organization for Standardization; 1999.

9- Ishigami K, Maeda R, Maeda M, Hamada H, Shou K, Shimada $A$, et al. Basic studies on visible light-cured resin as a denture base. Part 17. Transverse and tensile strengths of repaired denture base resin using a trial repair resin. J Nihon Univ Sch Dent. 1993;35(1):36-42.

10- Johnston EP, Nicholls JI, Smith DE. Flexure fatigue of 10 commonly used denture base resins. J Prosthet Dent.1981;46(5):478-83.

11- Keyf F, Uzun G. The effect of glass fibre-reinforcement on the transverse strength, deflection and modulus of elasticity of repaired acrylic resins. Int Dent J. 2000;50(2):93-7.

12- Kostoulas IE, Kavoura VT, Frangou MJ, Polyzois GL. The effect of length parameter on the repair strength of acrylic resin using fibers or metal wires. Gen Dent. 2008;56(1):51-5.

13- Kostoulas IE, Kavoura VT, Frangou MJ, Polyzois GL. Fracture force, deflection, and toughness of acrylic denture repairs involving glass fiber reinforcement. J Prosthodont. 2008;17(4):257-61.

14- Leavitt C, Boberick KG, Winkler S. Microtensile bond strength of resin-resin interfaces after 24-hour and 2-month soaking. J Oral Implantol. 2007;33(5):310-4.

15- Leong A, Grant AA. The transverse strength of repairs in polymethyl methacrylate. Aus Dent J. 1971;16(4):232-4.

16- Lin CT, Lee SY, Tsai TY, Dong DR, Shih YH. Degradation of repaired denture base materials in simulated oral fluid. J Oral Rehabil. 2000;27(3):190-8.

17- Mariatos G, Frangou M, Polyzois G, Papadopoulos T. Evaluation of shear bond strength of microwaveable acrylic resins in denture repair: a comparative study. Acta Odontol Scand. 2006;64(4):2448.

18- Miettinen VM, Vallittu PK, Docent DT. Water sorption and solubility of glass fiber-reinforced denture polymethyl methacrylate resin. J Prosthet Dent. 1997;77(5):531-4.

19- Pfeiffer P, An N, Schmage P. Repair strength of hypoallergenic denture base materials. J Prosthet Dent. 2008;100(4):292-301. 20- Polyzois GL, Tarantili PA, Frangou MJ, Andereopoulos AG. Fracture force, deflection at fracture and toughness of repaired denture resin subjected to microwave polymerization or reinforced with wire or glass fiber. J Prosthet Dent. 2001;86(6):613-9.

21- Rached RN, Powers JM, Del Bel Cury AA. Repair strength of autopolymerizing, microwave, and conventional heat-polymerized acrylic resins. J Prosthet Dent. 2004;92(1):79-82.

22- Rahal JS, Mesquita MF, Henriques GE, Nóbilo MAA. Influence of chemical and mechanical polishing on water sorption and solubility of denture base acrylic resins. Braz Dent J. 2004;15(3):225-30. 23- Stipho HD. Effect of glass fiber reinforcement on some mechanical properties of autopolymerizing polymethyl methacrylate. J Prosthet Dent. 1998;79(5):580-4. 
24- Stipho HD, Stipho AS. Effectiveness and durability of repaired acrylic resin joints J Prosthet Dent. 1987;58(2):249-53.

25- Takahashi Y, Chai J, Kawaguchi M. Equilibrium strengths of denture polymers subjected to long-term water immersion. Int J Prosthodont. 1999;12(4):348-52.

26- Vallittu PK. Effect of 180 week water storage on the flexural properties of E-glass and silica fiber acrylic resin composite. Int J Prosthodont. 2000;13(4):334-9.

27- Vallittu PK. Glass fiber reinforcement in repaired acrylic resin removable dentures: preliminary results of a clinical study. Quintessence Int. 1997;28(1):39-44.
28- Ward JE, Moon PC, Levine RA, Behrendt CL. Effect of repair surface design, repair material, and processing method on the transverse strength of repaired acrylic denture resin. J Prosthet Dent. 1992;67(6):815-820.

29- Yunus N, Rashid AA, Azmi LL, Abu-Hassan MI. Some flexural properties of a nylon denture base polymer. J Oral Rehabil. 2005;32:65-71.

30- Zappini G, Kammann A, Wachter WJ. Comparison of fracture tests of denture base materials. J Prosthet Dent. 2003;90(6):57885. 